\title{
Effect of Cr-C Coatings on the Corrosion Resistance of 304 Stainless Steel in the Molten Sodium Polysulfide
}

\author{
Yanjie Ren ${ }^{1, *}$, Chenyang Du ${ }^{l}$, HuayueDu ${ }^{l}$, Jian Chen ${ }^{l}$, Yuhang Zhao ${ }^{2, *}$
}

${ }^{1}$ School of Energy and Power Engineering, Changsha University of Science \& Technology, Changsha, Hunan 410114, China

${ }^{2}$ Research Center of ShenHua Zhunneng Comprehensive Resource Development Co. Ltd, Ordos, 010300, China

*E-mail: yjren@csust.edu.cn (Yanjie Ren), yuhangzhao8310@163.com (Yuhang Zhao)

doi: $10.20964 / 2021.02 .09$

Received: 16 September 2020/ Accepted: 6 November 2020 / Published: 31 December 2020

The corrosion of metallic containers in Na-S batteries cause an increase in resistance, a loss of battery capacity and cycling life limitations. In this paper, a $\mathrm{Cr}-\mathrm{C}$ coating was deposited on 304 stainless steel by a direct current magnetron sputtering technique. XRD analysis showed that the as-deposited $\mathrm{Cr}-\mathrm{C}$ coating mainly consisted of $\mathrm{Cr}_{3} \mathrm{C}_{2}, \mathrm{Cr}_{7} \mathrm{C}_{3}$ and $\mathrm{Cr}$. After corroding in molten sodium polysulfide at $350^{\circ} \mathrm{C}$ for $100 \mathrm{~h}, \mathrm{NaCrS}_{2}$ and $\mathrm{Cr}_{2} \mathrm{~S}_{3}$ were generated on the surface of the coating. The charge transfer resistance of this $\mathrm{Cr}-\mathrm{C}$ coating was higher than that of 304SS by approximately 3 orders of magnitude, showing improved corrosion resistance.

Keywords: Sodium sulfur batteries; Container; Cr-C coating; Electrochemical corrosion behaviour; Direct current magnetron sputtering

\section{$\underline{\text { FULL TEXT }}$}

(C) 2021 The Authors. Published by ESG (www.electrochemsci.org). This article is an open access article distributed under the terms and conditions of the Creative Commons Attribution license (http://creativecommons.org/licenses/by/4.0/). 